\title{
Erosion Wear Characteristics on Aroma Skin and Biochar Filled Polyester Composites
}

\author{
Manivannan J, Rajesh S, Mayandi K
}

\begin{abstract}
This work focused on erosion behaviour of pure polyester, aroma skin (5wt\%) and biochar (7.5wt\%) reinforced polyester composites. The hand-layup method is used to develop the composite plate. To investigate the erosion wear rate of the developed composite plates, the sized specimen is subjected to erosion studies. As per ASTM G76 the erosion test was done with the help of air jet erosion tester. To study the parameters of different reinforcement, impingement angle and impact velocity of the fabricated specimen. The erosion behaviour of particulate reinforced polyester composites is evaluated at two different reinforcement (aroma skin and biochar) and three different wt\% $(0 w t \%, 5 w t \%$ and $7.5 w t \%)$ at varying impingement angles $\left(30^{\circ}\right.$, $45^{\circ}, 60^{\circ}$ and $75^{\circ}$ ) for regular time intervals. The standoff distance, impact velocity and erodent discharge rate were kept constant. Alumina oxide is used as erodent material with the size of 50 $\mathrm{\mu m}$. From the result, it is observed that increase in impingement angle increase the erosion rates. Another observation is made that addition of reinforcement in matrix material also shows increase in wear rate of composite. In comparison of both aroma skin and biochar reinforced polymer composites, biochar enhances the erosion resistance of composite in all impingement angles.
\end{abstract}

Keywords : Aroma skin, Biochar, Polyester resin, Hand-layup, Erosion wear.

\section{INTRODUCTION}

In recent trend towards erosion wear performance of polymer composites by eroding the particle with various angles of impingement and impact velocities strike the material and damage the top surface which leads to material loss and changes in functional behaviour [1], [2]. Fibres and inorganic fillers are added in poly phenylene sulphide (PPS) which enhances the tribological properties [3], [4]. The erosive wear behaviour of fibre and particulate based polymers has not much investigated [5], [6]. Particle size, particle shape, velocity and impingement angle are some of the parameters to be consider in solid particle erosion test [7]. The friction and wear behaviour was studied in PEEK composites reinforced with fibre and particulate [8], [9]. Mahapatra et al. reported that increase in erosion rate of glass fibre reinforced composites is mostly due to impact velocity [10]. Suresh et.al studied that short fibre reinforced PEK composites with varying $\mathrm{wt} \%$ shows ductile nature in different impact

Revised Manuscript Received on December 30, 2019.

* Correspondence Author

Manivannan J*, Department of Mechanical Engineering,Kalasalingam Academy of Research and Education, Krishnankoil, India. Email: j.manivannan@klu.ac.in

Rajesh S, Department of Mechanical Engineering, Kalasalingam Academy of Research and Education, Krishnankoil, India. Email: s.rajesh@klu.ac.in

Mayandi K, Department of Mechanical Engineering, Kalasalingam Academy of Research and Education, Krishnankoil, India. Email: k.mayandi@klu.ac.in velocity and impingement angle. The erosion wear is increase with increase in wt $\%$ of fibre and maximum at $30^{\circ}$ impingement angle [11]. Sinmazcelik and Taskıran reported that the random orientation of short fibre and mineral powder based PPS composite with changes in impingement angle and impact velocity shows semi ductile nature. The rate of erosion is maximum at $60^{\circ}$ impingement angle [12]. Srivastava studied that the erosion rate is minimum in $2 \mathrm{~g}$ wheat flour filled GFRP [13]. The erosion performance of sheep wool reinforced polyester composites has not yet reported in the literature.In this present work, aroma skin and bichar reinforced polyester composites were selected as test specimen. The erosion performance of these composites were studied with constant standoff distance, impact velocity and erodent discharge rate and at varying wt $\%$ of reinforcement and impingement angles.

\section{EXPERIMENTAL DETAILS}

\section{A. Materials}

In this work aroma skin and biochar was chosen as reinforcement material and polyester resin as matrix material. The polyester resin and additional ingredients (MEKP \& CN) as catalyst and accelerator were brought from VB Pvt. Ltd., Chennai, Tamil Nadu, India. The Collected aroma skin and biochar contains dust particles and moisture content, it was removed by conventional method and dried at room temperature. Dried aroma skin and biochar is processed in ball mill to reduces the size. The processed aroma skin and biochar is sieved and the collected particles are in powder form in the range of $90-150 \mu \mathrm{m}$ for fabrication of composite.

\section{B. Fabrication of Composite}

To develop the composites, polyester resin as matrix, aroma skin and biochar are used as reinforcement material. By using hand-layup method the composite plates are developed. Initially, the glass mould is cleaned and applying wax over surface of the mould for easy removal of fabricated composite. $2 \% \mathrm{MEKP}$ and $2 \% \mathrm{CN}$ as catalyst and accelerator is stirred properly in the polyester resin followed by reinforcing material (aroma skin) and poured on the mould cavity. Finally the mould is closed and compressed conventionally. Composites of two different wt $\%(5 \mathrm{wt} \%$ and $7.5 \mathrm{wt} \%)$ as aroma skin and biochar reinforced polyester composite are prepared by using the same procedure. For proper curing, the castings are put under a constant load for 24 hours at room temperature. The fabricated composite is cut into suitable dimensions for erosion test as per ASTM standards. 


\section{Erosion Wear Characteristics on Aroma Skin and Biochar Filled Polyester Composites}

The process flow for this work is shown in Fig. 1 and the developed composite is shown in Fig. 2. The detailed wt $\%$ of reinforcement for the erosion test is shown in Table I and the testing parameters to conduct erosion studies is shown in Table II.

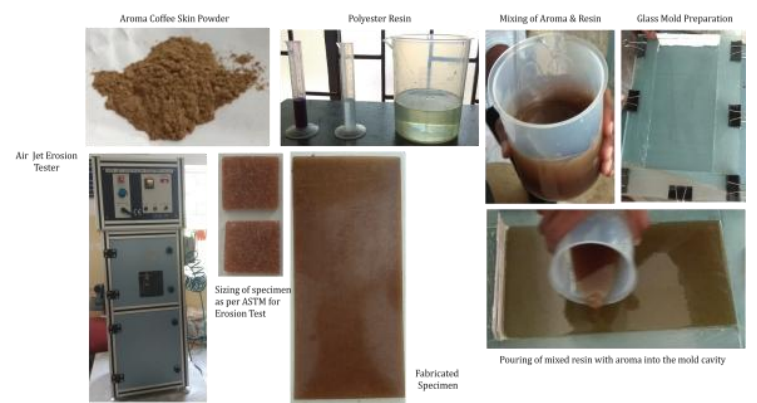

Fig. 1. Fabrication process

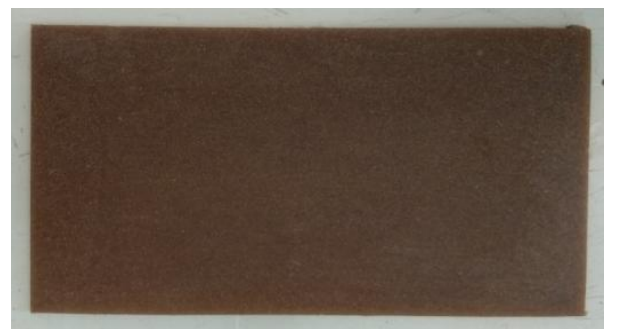

Fig. 2. Fabricated composite

Table- I: Detailed composition of the specimen

\begin{tabular}{|c|c|}
\hline Composite & Composition \\
\hline CP1 & Pure Polyester \\
\hline CP2 & Polyester $+5 \mathrm{wt} \%$ aroma skin \\
\hline CP3 & Polyester $+7.5 \mathrm{wt} \%$ biochar \\
\hline
\end{tabular}

Table- II: Erosion Test Parameters

\begin{tabular}{|c|c|c|c|}
\hline \multicolumn{2}{|c|}{ Fixed parameters } & \multicolumn{2}{|c|}{ Variable parameters } \\
\hline Erodent material & $\begin{array}{l}\text { Alumina } \\
\text { oxide }\end{array}$ & Time (mins) & $2,4,6 \ldots 60$ \\
\hline $\begin{array}{l}\text { Particle size of } \\
\text { erodent }(\mu \mathrm{m})\end{array}$ & 50 & \multirow{3}{*}{$\begin{array}{l}\text { Reinforcement } \\
(\mathrm{wt} \%)\end{array}$} & \multirow{3}{*}{$\begin{array}{l}\mathrm{PP}, 5 \mathrm{wt} \% \mathrm{AS} \text { and } \\
7.5 \% \mathrm{BC}\end{array}$} \\
\hline $\begin{array}{l}\text { Velocity of } \\
\text { impact }(\mathrm{m} / \mathrm{s})\end{array}$ & 100 & & \\
\hline $\begin{array}{l}\text { Erodent } \\
\text { discharge rate } \\
(\mathrm{g} / \mathrm{min})\end{array}$ & 3.3 & & \\
\hline $\begin{array}{l}\text { Testing } \\
\text { Temperature }\end{array}$ & RT & \multirow{3}{*}{$\begin{array}{l}\text { Angle of } \\
\text { impingement }\left(\alpha,{ }^{\circ}\right)\end{array}$} & \multirow{3}{*}{$30,45,60$ and 75} \\
\hline $\begin{array}{l}\text { Standoff } \\
\text { distance }(\mathrm{mm})\end{array}$ & 10 & & \\
\hline $\begin{array}{l}\text { Diameter of } \\
\text { nozzle }(\mathrm{mm})\end{array}$ & 3 & & \\
\hline
\end{tabular}

\section{RESULT AND DISCUSSION}

From the researchers investigations impact velocity, impingement angle, erodent size, shape, hardness and discharge rate, standoff distance and time have an important effect on erosion wear rate. This effect shows that a variation depends upon the testing of materials as ductile, brittle or semi-ductile. For brittle and ductile materials the erosion rate is maximum at an impingement angle of $15-20^{\circ}$ and $90^{\circ}$ and for semi ductile materials it was found that the erosion rate is maximum at angle of $45-60^{\circ}$. The delamination of fibres on surface of the materials is stop easily when increasing the erodent flow. The fact is increasing the striking speed of particle on the surface of material is the most important factors which leads to increase in wear rates, changing the angle of impingement should possess less wear rate as compare to speed variation. Besides striking speed, impingement angle and varying the size of erodent plays a vital role in increasing the rate of erosion. But, the effects of changes in direction of fibre leads to less wear rate when compared to other factors.

The most important parameters which influence erosive wear are impingement angle, impact velocity, erodent size, shape and discharge rate, standoff distance and time. The sequence of damage in fibre reinforced polymers due to erosive action. At the initial stage, material removal takes place in resin rich zones, further action which leads to breakage of fibres and laterally the fibre and matrix bond was damaged due to erosion.

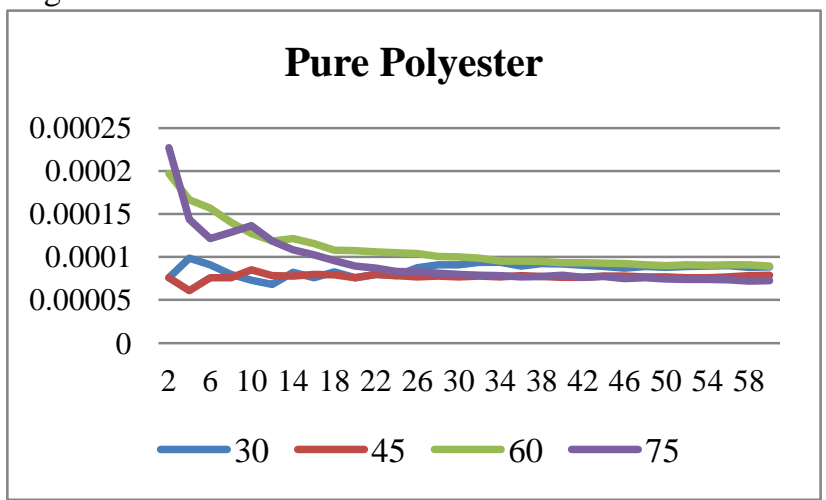

Fig. 3. Pure polyester

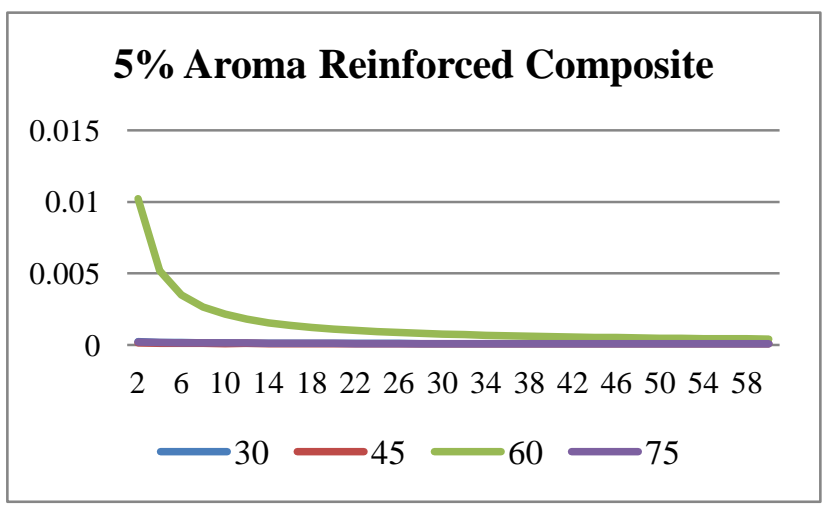

Fig. 4. 5\% Aroma Reinforced Composite

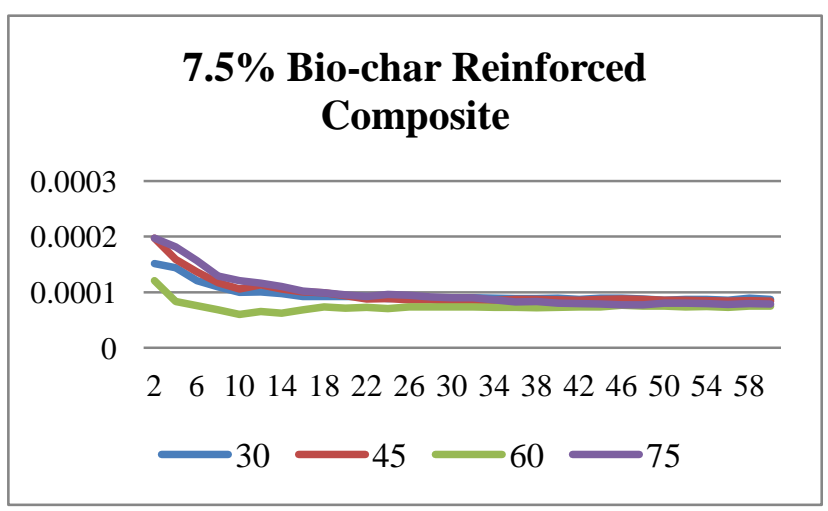

Fig. 5. 7.5\% Bio-char Reinforced Composite

From the above figures it clearly shown that the maximum erosion rate is occurs at an impingement angle of $75^{\circ}$ for pure polyester resin. 
While we adding the reinforcement of aroma coffee skin with $5 \mathrm{wt} \%$ the erosion rate is maximum at $60^{\circ}$ and we adding the reinforcement of biochar with $7.5 \mathrm{wt} \%$ the maximum erosion rate is takes place at an impingement angle of 45 and $75^{\circ}$.

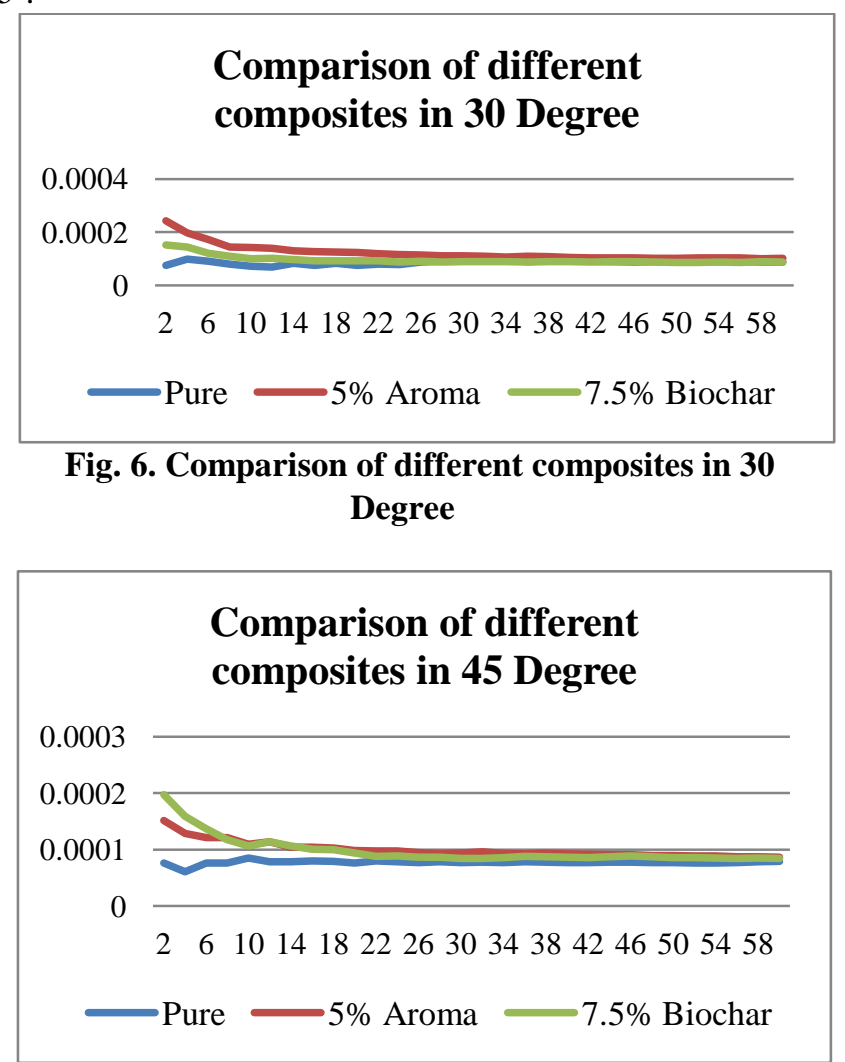

Fig. 7. Comparison of different composites in 45 Degree

\section{Comparison of different composites in 60 Degree}

0.02

0.01

0

$2 \quad 6 \quad 10141822 \quad 2630343842 \quad 46505458$

$\longrightarrow$ Pure $-5 \%$ Aroma $-7.5 \%$ Biochar

Fig. 8. Comparison of different composites in 60 Degree

\section{Comparison of different composites in 75 Degree}

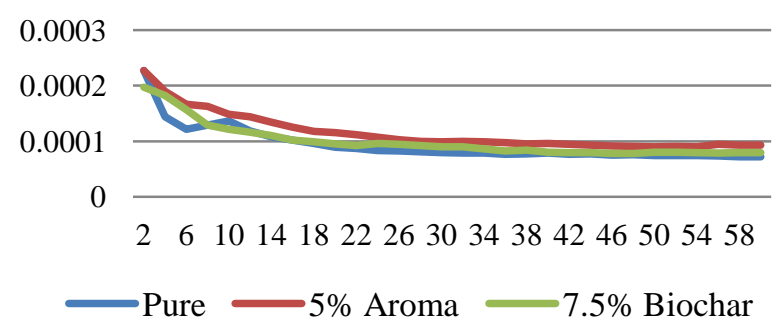

Fig. 9. Comparison of different composites in 75 Degree
A comparison graph is plotted for four different angles $(30,45,60$ and 75$)$ with varying wt $\%$ of the composites (Pure, 5wt\% Aroma and 7.5wt\% Biochar). From the comparative graphs it is understand that the erosion rate of $5 \mathrm{wt} \%$ aroma is maximum at an impingement angle of $30^{\circ}$. At the angle of impingement is $45^{\circ}$ the maximum erosion rate is occurs in $7.5 \mathrm{wt} \%$ of biochar. The erosion rate for $5 \mathrm{wt} \%$ of aroma is maximum at an angle of $60^{\circ}$ and the maximum erosion rate is takes place at an angle of $75^{\circ}$ for pure polyester resin and $5 \mathrm{wt} \%$ of aroma.

\section{CONCLUSION}

The following conclusions are made for the erosion performance of sheep wool reinforced polyester composites.

1) Fabrication of particulate reinforced polyester composites consisting of aroma and biochar as reinforcement in polyester resin is possible in simple hand lay-up technique.

2) Increases the wt\% of particle reinforcement significantly alter the erosion performance of the composites.

3) Increases the angle of impingement increase in wear rate of the composite.

4) The erosion wear performance of polyester composites improves with the incorporation of particulate fillers. Among the three different weight percentage (Pure, $5 \mathrm{wt} . \%$ aroma and $7.5 \mathrm{wt} . \%$ biochar) $7.5 \mathrm{wt} . \%$ biochar gives the better erosive wear resistance in all impingement angles when compare to other composites.

5) Erosion wear behaviour of these composites improves with addition of biochar reinforcement. It may be recommended for the application of light weight vehicles because of its nature as biodegradable and eco-friendly.

\section{REFERENCES}

1. I. Finnie, Some reflections on the past and future of erosion, Wear; vol 186, 187(1), pp. 1-10, 1995

2. G. Sundararajan, M. Roy, Solid particle erosion behaviour of metallic materials at room and elevated temperatures, Tribol Int, vol. 30(5), pp. 339-59, 1997

3. I. Mutlu,C. Oner, F. Findik, Boric acid effect in phenolic composites on tribological properties in brake linings, Mater Des, vol. 28, pp. 480-7, 2007.

4. I. Mutlu,C. Oner, F. Findik, Wear performance of some phenolic composites with boric acid, Ind Lubricat Technol, vol. 59(1), pp. 38-45, 2007.

5. S. Biswas, A. Satapathy, A study on tribological behavior of alumina-filled glass epoxy composites using Taguchi experimental design, Tribol Trans, vol. 53, pp. 520-32, 2010.

6. A. Patnaik, A. Satapathy, S.S. Mahapatra, R.R. Dash, Implementation of Taguchi design for erosion of fiber reinforced polyester composite systems with SiC filler, J Reinf Plast Compos, vol. 27(10), pp 1093-111, 2008.

7. V.K. Srivastava, A.G. Pawar, Solid particle erosion of glass fiber reinforced flyash filled epoxy resin composites, Compos Sci Technol, vol. 66, pp. 3021-8, 2006.

8. M. Cirino, R.B. Pipes, K. Friedrich, The abrasive wear behaviour of continuous fibre polymer composites, J Mater Sci, vol. 22, 2481-2492, 1987.

9. Q.H. Wang, Q.J. Xue, W.M. Liu, J.M. Chen, The friction and wear characteristics of nanometer SiC and PTFE filled PEEK, Wear, vol. 243, pp. 140-146, 2000

10. S.S. Mahapatra, A. Patnaik, A. Satapathy, Taguchi method applied to parametric appraisal of erosion behavior of GF-reinforced polyester composites, Wear, vol. 265, pp. 214-22, 2008 
11. A. Suresh, A.P. Harsha, M.K. Ghosh, Erosion studies of short glass fiber-reinforced thermoplastic composites and prediction of erosion rate using ANNs, J Reinf Plast Comp, vol. 29(11), pp. 1641-52, 2010.

12. T. Sinmazcelik, I. Taskıran, Erosive wear behaviour of polyphenylenesulphide (PPS) composites, Mater Des, vol. 28, pp. 2471-7, 2007.

13. V.K. Srivastava, Effects of wheat starch on erosive wear of E-glass fiber reinforced epoxy resin composite materials, Mater Sci Eng A, vol. 435 , 436, pp. 282-7, 2006.

\section{AUTHORS PROFILE}

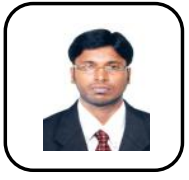

Mr. J. Manivannan completed his B.E. Mechanical Engineering in K.S.Rangasamy College of Technology, Tiruchengode. $\mathrm{He}$ has completed his M.Tech (CAD/CAM) in Kalasalingam University, Krishnankoil. $\mathrm{He}$ is serving as Assistant Professor in same institute and doing his research as part time mode. His area of research as performance studies on polymer matrix composites. He has published 4 Journal papers (Impact Factor and Scopus Indexed) and more than 15 International Conference papers.

Dr. S. Rajeshcompleted his B. E in Mechanical Engineering and M.E. (CAD) from AlagappaChettiar Government College of Engineering and Technology, Karaikudi, Ph.D(Machining of Metal of Matrix Composites) from Kalasalingam Academy of Research and Education, Krishnankoil in the year 2014, and thesis highly recommended by both the examiners. Inthe year 2018, I have received DST - AMT project for the worth of Rs. 25,72,400 and completed one IEDC project for the worth of Rs. 1,00,000. He has published more than 25 Journal papers (Impact Factor and Scopus Indexed) and more than 40 International Conference papers.

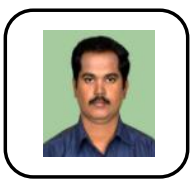

Dr.K.Mayandireceived his B.E. (2007)in Mechanical Engineering and M.E. (2011) in Engineering Design from Anna University, Chennai and obtained the Ph.D (2016) from Kalasalingam University, Krishnankoil. $\mathrm{He}$ is working as an Associate Professor in the School of Automotive and Mechanical Engineering at Kalasalingam Academy of Research and Education, Krishnankoil, Madurai, India. His research interest on characterization of natural fibres and utilized the natural fibres as reinforcement with polymer composites materials for biodegradable applications. Recently focuses the research on fracture analysis of layered polymer composites materials and also involves the works on fabrication and testing of filament winding polymer composites tube for medium load applications areas. He has published 12 International Journals and 2 Book Chapters published in Elsevier and Wiley publications. 